\title{
Determination of the distribution of conduction velocities in workers exposed to lead, zinc, and copper
}

\author{
S ARAKI, K YOKOYAMA, K MURATA, AND H AONO \\ From the Department of Public Health and Hygiene, Medical College of Oita, Hazama-machi, Oita 879-56, \\ Japan
}

\begin{abstract}
By measuring the distribution of conduction velocities (DCV) in sensory fibres of the median nerve, the effects of asymptomatic increased lead, zinc, and copper absorption on the conduction velocities of slower and faster nerve fibres were examined in 20 gun metal founders with blood lead (BPb) concentrations of 22-59 (mean 39) $\mu \mathrm{g} / \mathrm{dl}(1 \cdot 1-2.8$ (mean 1.9) $\mu \mathrm{mol} / \mathrm{l})$. The results indicated that the conduction velocities of slower fibres were inversely affected by lead absorption, resulting in a significant reduction in the velocities at the BPb level of $40-59 \mu \mathrm{g} / \mathrm{dl}$; on the other hand, the conduction velocities of faster fibres and the conventional sensory nerve conduction velocity were presumably positively affected by zinc absorption without a significant reduction in the velocities of faster fibres. It is suggested that assessment of the possible antagonistic effect of zinc is essential when conduction velocities are not decreased in lead exposed workers.
\end{abstract}

Seppäläinen and coworkers have shown that slower and maximal motor nerve conduction velocities decrease at levels of occupational lead exposure previously considered "safe,"-that is, at blood lead (BPb) concentrations below $70 \mu \mathrm{g} / \mathrm{dl}(3.4 \mu \mathrm{mol} / \mathrm{l}){ }^{1}$ We have shown that the maximal sensory nerve conduction velocity is also affected in adults with asymptomatic increased lead absorption. ${ }^{2}$ These observations, although they have not been made in all published reports, ${ }^{3-6}$ have in the main been confirmed by subsequent investigations. ${ }^{7-16}$

Peripheral nerve trunks consist of several thousand myelinated nerve fibres with slower and faster conduction velocities in parallel to the fibre diameters. The conventional methods for determining conduction velocities yield only two discrete values that reflect the maximal and slower velocities of fibres in the nerve trunk; the function of the vast majority of fibres cannot be directly assessed. In 1979 three groups of investigators ${ }^{17-19}$ independently introduced new and different transcutaneous techniques to derive the distribution of conduction velocities (DCV) of large myelinated fibres (alpha fibre group) by means of computer analysis. Recently, we have established one of these methods in our laboratory. ${ }^{20}$ In the present study our technique is applied to work-

Accepted 27 August 1985 ers with asymptomatic increased lead, zinc, and copper absorption.

\section{Subjects and methods}

\section{SUBJECTS}

The nature of the procedure in the present study was fully explained to all subjects, and the study was carried out with their informed consent. The 20 subjects, aged 34 to 59 (mean 48), were male gun metal founders employed at a metal factory for two to 17 (mean 10) years; their $\mathrm{BPb}$ concentrations ranged from 22 to 59 (mean 39) $\mu \mathrm{g} / \mathrm{dl}$. In nine of the workers (high lead group) the BPb was $40 \mu \mathrm{g} / \mathrm{dl}$ or above; in the remaining workers (low lead group) it was below $40 \mu \mathrm{g} / \mathrm{dl}$. The plasma zinc (PZn) concentrations ranged from 73 to 111 (mean 88) $\mu \mathrm{g} / \mathrm{dl}(11.2$ to 17.0 (mean 13.5) $\mu \mathrm{mol} / \mathrm{l}$ ) in 20 gun metal founders; the plasma copper (PCu) concentrations were 64 to 126 (mean 91$) \mu \mathrm{g} / \mathrm{dl}(10 \cdot 1$ to 19.8 (mean 14.3$) \mu \mathrm{mol} / \mathrm{l}$ ). These $\mathrm{BPb}, \mathrm{PZn}$, and $\mathrm{PCu}$ concentrations were significantly higher than those in all (16) male steel foundry workers at the same factory - that is, 8-20 (mean 13) $\mu \mathrm{g} / \mathrm{dl}$ for $\mathrm{BPb}, 54-97$ (mean 72) $\mu \mathrm{g} / \mathrm{dl}$ for $\mathrm{PZn}$, and 50-100 (mean 73) $\mu \mathrm{g} / \mathrm{dl}$ for $\mathrm{PCu}$, respectively $(p<0.05)$. All gun metal founders drank alcohol equivalent to $0-760 \mathrm{ml}$ of $100 \%$ ethanol a week (mean 283); six of them had a history of metal fume fever. None of the subjects had specific signs and symptoms indicative of clinical lead poisoning or 
(a) CAPs at wrist (above) and elbow (below)

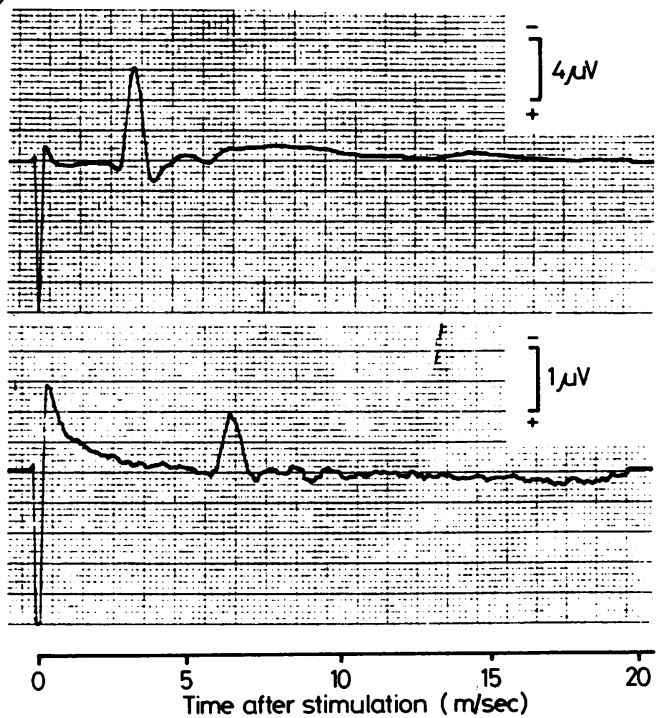

(b) SFAP calculated

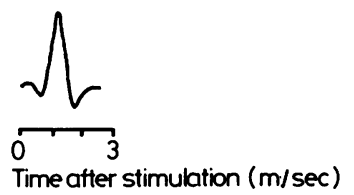

Fig 1 Compound action potentials (CAPs) recorded from median nerve at wrist and elbow after stimulation of second finger in a gun metal founder, and calculated single fibre action potential ( $S F A P$, relative amplitude) corresponding to conduction velocity of $67.5 \mathrm{~m} / \mathrm{sec}$.

of neurological or other endogenous disorders; none was exposed in their workplace to such chemicals as arsenic and solvents, which might also have neurotoxic effects.

Control subjects for electrophysiological studies were 20 male "healthy" adults neither occupationally exposed to lead, zinc, or copper nor having neurological disorders; ages ranged from 31 to 58 (mean 45). There were no significant differences in age, height, skin temperature, and alcohol and tobacco consumption between either of the high and low lead groups and the 20 control subjects at the time of electrophysiological studies (Wilcoxon's rank sum test, $p$ $>0.05)$.

\section{ELECTROPHYSIOLOGICAL STUDIES}

The DCV was measured by the same method reported previously by us (a modified method of Barker et al). ${ }^{1720}$ The study was conducted in a warm laboratory $\left(28-32^{\circ} \mathrm{C}\right)$ by the use of a Medelec MS-92 two channel electromyograph; skin temperature was $\stackrel{8}{8}$ maintained in the range of $32-35^{\circ} \mathrm{C}$ for all subjects. The right median nerve was stimulated repeatedly $\stackrel{D}{\rightarrow}$ with stainless ring cathode and anode electrodes, tied 0 around the proximal and distal interphalangeal joints 흠 of the second finger respectively, with a 70 to $100 \mathrm{~V} \frac{\bar{c}}{\frac{5}{\sigma}}$ square wave pulse of $0.2 \mathrm{msec}$ duration. The com- $\mathbb{D}$ pound action potential (CAP) was picked up with surface electrodes at the wrist and the elbow. The responses were averaged 200 to 1000 times until no $\vec{\circ}$ changes were discerned in the recorded CAP on the $\overrightarrow{\vec{\omega}}$ oscilloscope or electromyograph. Typical records of $\underset{\sigma}{\omega}$ the CAP are illustrated in fig 1 together with the single $\stackrel{\odot}{\stackrel{D}{ }}$ fibre action potential calculated. The CAP was digitised with a sampling interval of $0.04 \mathrm{msec}$ and stored for DCV analysis on the discs of the Hitachi MB6891 programmable electric calculator.

The DCV was calculated by the double conduction

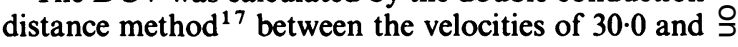
$77.5 \mathrm{~m} / \mathrm{sec}$ with an interval of $2.5 \mathrm{~m} / \mathrm{sec}$ from the two CAPs recorded at the wrist and the elbow. The calculation was continued until the estimated numbers of nerve fibres with varying conduction velocities converged to the values that did not change significantly

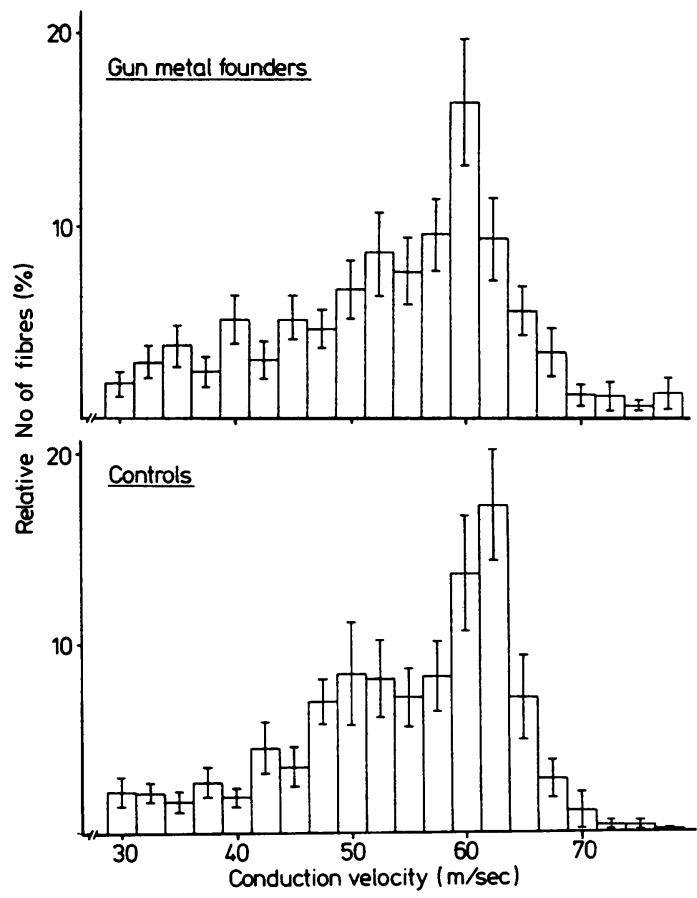

Fig 2 Distribution of conduction velocities in 20 gun metal founders and 20 control subjects (averages and standard errors). 


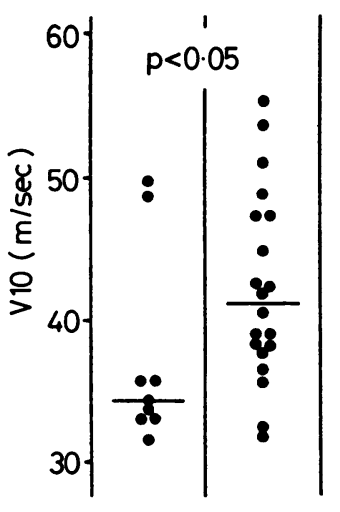

High lead Control group group

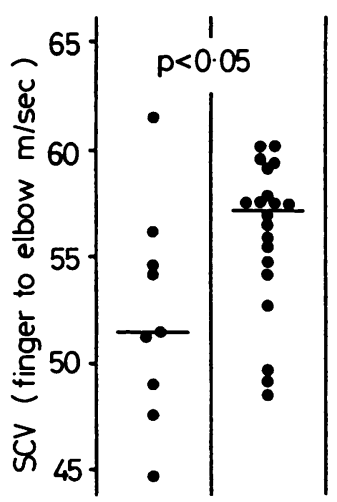

High lead Control group group
Fig 3 Differences in distribution of conduction velocity (V10 velocity) and sensory nerve conduction velocity (SCV) between the high lead group of gun metal founders (nine subjects) and 20 control subjects (Wilcoxon's rank sum test). Transverse line indicates median values. SCV (finger to wrist) for high lead group (38.7-53.0 m/sec, median 44.6) was also significantly lower than that for control subjects $(36.0-62.9 \mathrm{~m} / \mathrm{sec}$, median 50.3$)(p<0.05)$.

from the preceding ones with further calculation (Wilcoxon's signed rank test, $p>0.05$ ) and until the correlation coefficient between the numbers of nerve fibres on two successive calculations became significant $(\mathrm{p}<0.05)$.

The calculated DCV was expressed by the following parameters: the conduction velocities below which $5,10,20,30,40,50,60,70,80$, and $90 \%$ of active nerve fibres lie (V5, V10, V20, V30, V40, V50, V60, $\mathrm{V70}, \mathrm{V80}$, and V90 velocities); arithmetic mean of the conduction velocities (Vmean); and mode of the conduction velocities (Vpeak).

The maximal sensory nerve conduction velocity of the right median nerve (SCV) was calculated from the two CAPs for the areas from the finger to the wrist and to the elbow. ${ }^{2}$

To ascertain daily variations in the DCV and SCV, we performed the measurement over a period of 15 days in a 24 year old "healthy" student. We found that the coefficients of variation were $2.0-4.7 \%$ for the V5 to V90 velocities; $3.4 \%$ for Vmean; $0.0 \%$ for Vpeak; $4.5 \%$ for SCV (finger to wrist); and $2.6 \%$ for SCV (finger to elbow).

\section{COLLECTION AND ANALYSIS OF BLOOD}

AND URINE SAMPLES

Blood samples were collected just before electrophysiological studies and before the start of 24 hour urine collection. Calcium disodium ethylenediamine tetra-acetate was then injected intravenously in a dos- age of $20 \mathrm{mg}$ ( $53.4 \mu \mathrm{mol})$ per kg body weight in $250 \mathrm{ml}$ of $5 \%$ glucose solution; 24 hour mobilisation yields of lead, zinc, and copper in urine (MPb, MZn, and $\mathrm{MCu})$ were measured. The concentrations of lead in whole blood, plasma, and erythrocytes $(\mathrm{BPb}, \mathrm{PPb}$, and $\mathrm{EPb}$ ), the concentrations of zinc and copper in plasma and erythrocytes (PZn, EZn, PCu, and ECu), and the amount of each metal spontaneously excreted in urine for 24 hours ( $\mathrm{UPb}, \mathrm{UZn}$, and $\mathrm{UCu}$ ), together with $\mathrm{MPb}, \mathrm{MZn}$, and $\mathrm{MCu}$ were measured by atomic absorption spectrophotometry (Hitachi polarised Zeeman atomic absorption spectrophotometer $180-80$ ) by the methods described in our previous reports. $^{2122}$

\section{Results}

The DCVs in 20 gun metal founders and in 20 control subjects are illustrated in fig 2 . The V10 velocity and SCVs were significantly slowed in the high lead group of gun metal founders (fig 3). There were no significant differences in other parameters of DCV between the high lead group and control subjects; similarly, in all parameters between the low-lead group and control subjects $(p>0.05)$.

The V5, V10, and V20 velocities were inversely correlated with indicators of lead absorption (MPb and $\mathrm{BPb}$ ) as well as $\mathbf{P C u}$ in $\mathbf{2 0}$ gun metal founders (fig 4 and table); the Spearman's rank correlations for these relations were also significant $(-0.615$ for V5 velocity and $\mathrm{MPb}, \mathrm{p}<0.01 ;-0.518$ for $\mathrm{V} 10$ velocity and $\mathrm{BPb}, \mathrm{p}<0.05)$. $\mathrm{PCu}$ was positively correlated with $\mathrm{MPb}(\mathrm{r}=0.536, \mathrm{p}<0.05)$. On the other hand, the V80, V90, and Vpeak velocities and SCVs were positively correlated with indicators of zinc absorption (UZn and EZn) (fig 4 and table). The SCV (finger to elbow) was significantly correlated with the V70, V80, and V90 velocities $(r=0.447,0.579$, and 0.646 , respectively, $\mathrm{p}<0.05$ ).

Factors significantly correlated with the distribution of conduction velocities and with sensory nerve conduction velocity in 20 gun metal founders $\dagger$

\begin{tabular}{|c|c|}
\hline $\begin{array}{l}\text { Conduction } \\
\text { velocity }\end{array}$ & $\begin{array}{l}\text { Factors (Pearson's product moment } \\
\text { correlation, } r \text {, in parentheses) }\end{array}$ \\
\hline $\begin{array}{l}\text { V5 } \\
\text { V10 } \\
\text { V20 } \\
\text { V80 } \\
\text { V90 } \\
\text { Vpeak }\end{array}$ & $\begin{array}{l}\mathrm{MPb}\left(-0.595^{* *}\right) ; \mathrm{PCu}\left(-0.450^{*}\right) \\
\mathrm{BPb}\left(-0.459^{*}\right) ; \mathrm{MPb}\left(-0.542^{*}\right) ; \mathrm{PCu}\left(-0.497^{*}\right) \\
\mathrm{MPb}\left(-0.449^{*}\right) ; \mathrm{PCu}\left(-0.459^{*}\right) \\
\text { UZn }\left(0.459^{*}\right) \\
\text { UZn }\left(0.482^{*}\right) \\
\text { UZn }\left(0.514^{*}\right)\end{array}$ \\
\hline $\begin{array}{l}\text { SCV (finger to } \\
\text { wrist) } \\
\text { SCV (finger to } \\
\text { elbow) }\end{array}$ & $\begin{array}{l}\operatorname{EZn}\left(0.452^{*}\right) \\
\operatorname{UZn}\left(0.455^{*}\right)\end{array}$ \\
\hline
\end{tabular}



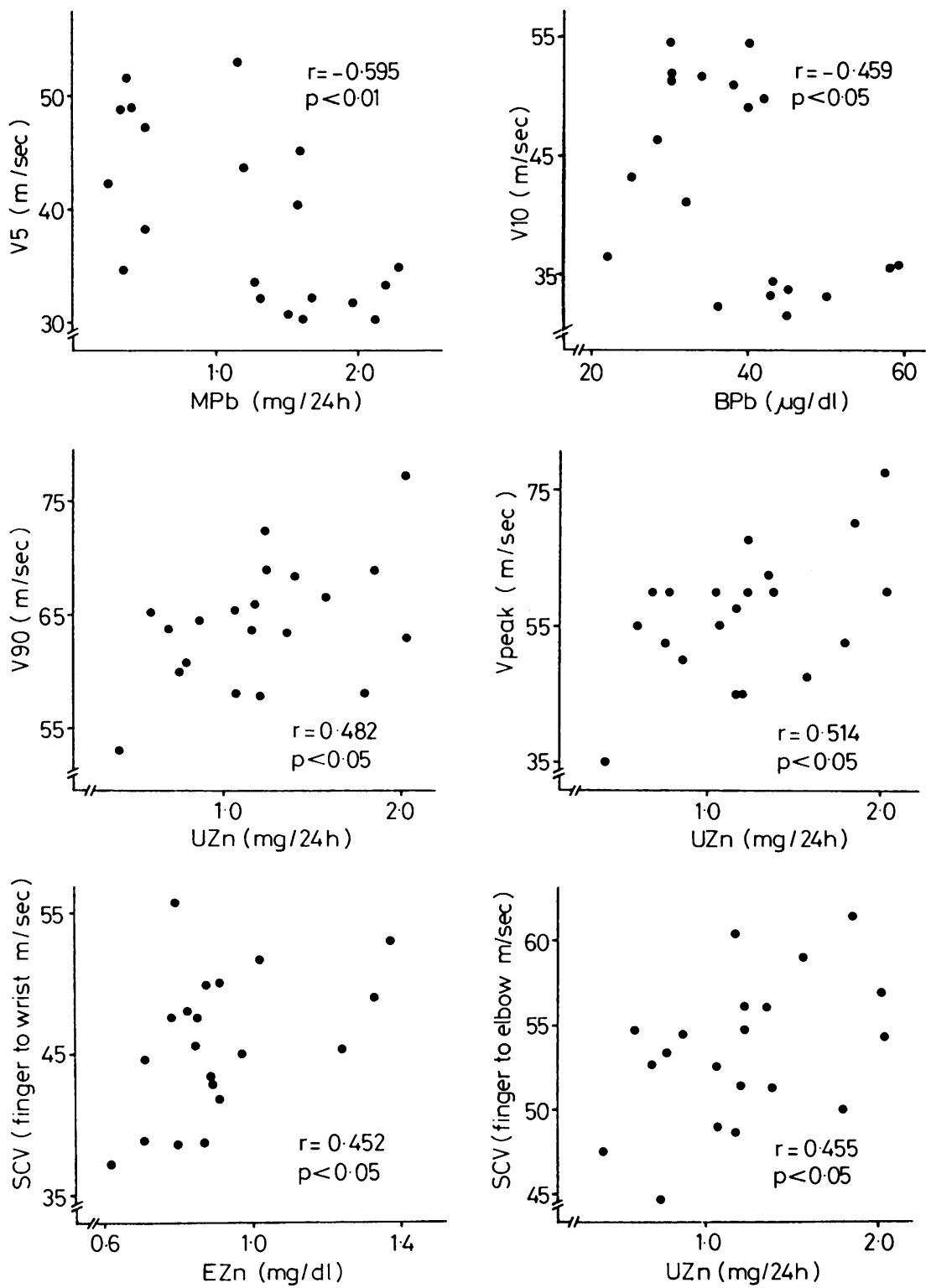

Fig 4 Relations between distribution of conduction velocities (V5, V10,V90, and Vpeak velocities) or sensory nerve conduction velocity (SCV) and indicators of lead and zinc absorption (MPb, BPb, UZn, and EZn) in 20 gun metal founders. $r$ indicates Pearson's product moment correlation. One $\mu \mathrm{g} /$ dl of BPb corresponds to $0.05 \mu \mathrm{mol} / \mathrm{l} ; 1 \mathrm{mg} / 24 \mathrm{~h}$ of $\mathrm{MPb}$ to $4.8 \mu \mathrm{mol} / 24 \mathrm{~h} ; 1 \mathrm{mg} / 24 \mathrm{~h}$ of $\mathrm{UZn}$ to $15.3 \mu \mathrm{mol} / 24 \mathrm{~h}$; and $1 \mathrm{mg} / \mathrm{dl}$ of $\mathrm{EZn}$ to $0.15 \mathrm{mmol} / \mathrm{l}$. 


\section{Discussion}

This is probably the first report to disclose the significant effects of lead and zinc on the DCV; it is suggested that DCV analysis is useful for evaluation of subclinical lead neuropathy. Sax et al $^{23}$ applied another technique of DCV analysis (method of Kovacs $e a^{19}$ ) to four lead exposed subjects, but failed to find a consistent pattern of the changes. This is probably due to the small sample size or a difference of their technique from ours.

The V5, V10, and V20 velocities were significantly correlated with two or three (15 or $23 \%)$ of all the 13 indicators of lead, zinc, or copper absorption examined; these indicators were consistent $(\mathrm{MPb}, \mathrm{PCu}$ (and $\mathrm{BPb}$ )). Furthermore, the significance level for the V5 velocity was substantially high $(\mathrm{p}<0.01)$. These results, together with a significant slowing of the V10 velocity, suggest that slower fibre conduction velocities of the sensory median nerve were inversely affected by lead, resulting in a conduction delay at the $\mathrm{BPb}$ level of $40-50 \mu \mathrm{g} / \mathrm{dl}$. Significant correlations of $\mathrm{BPb}$ and $\mathrm{MPb}$ with conventional motor and sensory nerve conduction velocities have been shown in some studies. $^{281011}$ The inverse relation of $\mathrm{PCu}$ to the V5, V10, and V20 velocities is considered to reflect lead effects on the slower fibre velocities, as $\mathrm{PCu}$ was positively correlated with $\mathrm{MPb}$.

Seppäläinen et al have shown that the conduction velocity of the slower motor fibres of the ulnar nerve (CVSF) is particularly sensitive to lead. ${ }^{124}$ It appears that both motor and sensory slower fibres are sensitive to lead. Histological studies are needed to clarify the changes underlying these physiological alterations.

Faster fibre conduction velocities (V80 and V90 velocities), on the other hand, were positively correlated with UZn; similarly, SCVs were correlated with EZn and UZn. It is thus suggested that zinc antagonised a lead induced conduction delay in these nerve fibres. These data are consistent with another observation by us that zinc possibly antagonised the effects of lead on the conventional motor and sensory conduction velocities of the radial nerve in lead exposed workers. ${ }^{25}$ As no indicator of lead and copper absorption was significantly correlated with indicators of zinc absorption in the present study ( $p>$ 0.05 ), the effects of zinc on the nerve conduction velocities are considered to be independent of the effects of those metals. Alternatively, the correlations between zinc absorption and nerve conduction velocities might have been random results; therefore, epidemiological and clinical studies with a greater number of subjects are required.

The extent to which faster fibre conduction velocities were affected by lead remains unclarified in this study. Further studies with lead workers free from zinc exposure might disclose the relative strength of lead effects on the faster and slower fibres. These studies by the use of DCV analysis might terminate one of the long lasting controversies over the effects of lead on peripheral nerve conduction velocity-that is, whether or not the conduction velocity of the slower nerve fibres is more sensitive to lead than that of the fastest fibre. ${ }^{1926}$ Similarly, we have no convincing explanation to offer for the difference in the strength of lead effects between faster fibre conduction velocities and SCVs.

A few investigators have failed to find significant reductions in the conventional nerve conduction velocities in workers with asymptomatic increased lead absorption. ${ }^{3-6}$ In at least one of their reports, ${ }^{3}$ however, there was simultaneous exposure to lead and zinc. It is thus suggested that investigators estimate the possible antagonistic effect of zinc when no reduction in nerve conduction velocities is found in workers exposed to lead.

We thank Miss $\mathrm{S}$ Yasumi for her help in preparing the manuscript.

\section{References}

${ }^{1}$ Seppäläinen AM, Tola S, Hernberg S, Kock B. Subclinical neuropathy at "safe" levels of lead exposure. Arch Environ Health 1975;30:180-3.

${ }^{2}$ Araki S, Honma T. Relationships between lead absorption and peripheral nerve conduction velocities in lead workers. Scand $J$ Work Environ Health 1976;4:225-31.

${ }^{3}$ Paulev P-E, Gry C, Døssing M. Motor nerve conduction velocity in asymptomatic lead workers. Int Arch Occup Environ Health 1979;43:37-43.

${ }^{4}$ Baloh RW, Spivey GH, Brown CP, et al. Subclinical effects of chronic increased lead absorption-a prospective study. II. Results of baseline neurologic testing. $J$ Occup Med 1979;21:490-6.

${ }^{5}$ Spivey GH, Baloh RW, Brown CP, et al. Subclinical effects of chronic increased lead absorption-a prospective study. III. Neurologic findings at follow up examination. $J$ Occup Med 1980;22:607-12.

${ }^{6}$ Nielsen CJ, Nielsen VK, Kirkby H, Gyntelberg F. Absence of peripheral neuropathy in long-term lead-exposed subjects. Acta Neurol Scandinav 1982;65:241-7.

${ }^{7}$ Repko JD, Corum CR, Jones PD, Garcia LS, Jr. The effects of inorganic lead on behavioral and neurologic function. Washington, DC: US Government Printing Office, 1978.

${ }^{8}$ Seppäläinen AM, Hernberg S, Kock B. Relationship between blood lead levels and nerve conduction velocities. $\mathrm{Neu}$ rotoxicology 1979;1:313-32.

${ }^{9}$ Buchthal F, Behse F. Electrophysiology and nerve biopsy in men exposed to lead. Br J Ind Med 1979;36:135-47.

${ }^{10}$ Ashby JAS. A neurological and biochemical study of early lead poisoning. Br J Ind Med 1980;37:133-40.

${ }^{11}$ Araki S, Honma T, Yanagihara S, Ushio K. Recovery of slowed nerve conduction velocity in lead-exposed workers. Int Arch Occup Environ Health 1980;46:151-7.

12 Bordo BM, Filippini G, Massetto N, Musicco M, Boeri R. Electrophysiological study of subjects occupationally exposed to 
lead and with low levels of lead poisoning. Scand J Work Environ Health 1982;8(supp 1):142-7.

${ }^{13}$ Seppäläinen AM, Hernberg S, Vesanto R, Kock B. Early neurotoxic effects of occupational lead exposure: a prospective study. Neurotoxicology 1983;4:181-92.

${ }^{14}$ Singer R, Valciukas JA, Lilis R. Lead exposure and nerve conduction velocity: the differential time course of sensory and motor nerve effects. Neurotoxicology 1983;4:193-202.

${ }^{15}$ Rosén I, Wildt K, Gullberg B, Berlin M. Neurophysiological effects of lead exposure. Scand J Work Environ Health 1983;9:431-41.

${ }^{16}$ Jeyaratnam J, Devathasan G, Ong CN, Phoon WO, Wong PK. Neurophysiological studies on workers exposed to lead. $\mathrm{Br} J$ Ind Med 1985;42:173-7.

${ }^{17}$ Barker AT, Brown BH, Freeston IL. Determination of the distribution of conduction velocities in human nerve trunks. IEEE Trans Biomed Eng 1979;BME-26:76-81.

${ }^{18}$ Cummins KL, Perkel DH, Dorfman LJ. Nerve fiber conductionvelocity distributions. I. Estimation based on the single-fiber and compound action potentials. Electroencephalogr Clin Neurophysiol 1979;46:634-46.

${ }^{19}$ Kovacs ZL, Johnson TL, Sax DS. Estimation of the distribution of conduction velocities in peripheral nerves. Comput Biol Med 1979;9:281-93.

${ }^{20}$ Yokoyama K, Araki S, Murata K, Aono H. The effects of lead on the distribution of conduction velocities (DCV) in man. Japanese Journal of Hygiene 1985;40:339. (In Japanese.)

${ }^{21}$ Araki S, Aono H, Fukahori M, Tabuki K. Behavior of lead and zinc in plasma, erythrocytes, and urine and ALAD in erythrocytes following intravenous infusion of CaEDTA in lead workers. Arch Environ Health 1984;39:363-7.

${ }^{22}$ Aono $\mathrm{H}$, Araki S. The effects of CaEDTA injection on lead, zinc, copper and ALAD in erythrocyte, plasma and urine in leadexposed workers: a 24-h observation. Int Arch Occup Environ Health 1984;55:13-8.

${ }^{23}$ Sax DS, Kovacs ZL, Johnson TL, Feldman RG. Clinical applications of the estimations of nerve conduction velocity distributions. In: Dorfman LJ, Cummins KL, Leifer LJ, eds. Conduction velocity distributions: a population approach to electrophysiology of nerve. New York: Alan R Liss, Inc, 1981:113-36.

${ }^{24}$ Seppäläinen AM, Hernberg S. Sensitive technique for detecting subclinical lead neuropathy. Br J Ind Med 1972;29:443-9.

${ }^{25}$ Araki S, Murata K, Aono H. Antagonistic effects of lead, zinc and copper on peripheral nerve conduction velocity in metal workers. Proceedings of Kyushu regional meeting of Japan Association of Industrial Health in 1985. Jpn J Ind Health 1985;27:346. (In Japanese.)

${ }^{26}$ Cooper GP, Sigwart CD. Neurophysiological effects of lead. In: Singhal RL, Thomas JA, eds. Lead toxicity. Baltimore: Urban \& Schwarzenberg, 1980:401-23. 